\title{
Pesquisa como princípio educativo: contribuições das perguntas dos estudantes para a aprendizagem de Química
}

\section{La investigación como principio educativo: contribuciones de las preguntas de los estudiantes para el aprendizaje de la Química}

Simone Mertins (simonemertins@hotmail.com)

Pontifícia Universidade Católica do Rio Grande do Sul

Lorita Aparecida Veloso Galle (loritaveloso@hotmail.com)

Pontifícia Universidade Católica do Rio Grande do Sul

Carla Melo da Silva (carlamelodasilva2015@gmail.com)

Pontifícia Universidade Católica do Rio Grande do Sul

Resumo: Este estudo de abordagem qualitativa, pretende responder a seguinte indagação: de que modo perguntas sobre combustíveis, propostas por estudantes, podem contribuir para a aprendizagem de Química Orgânica? Esta pesquisa, com abordagem qualitativa, foi efetuada no contexto do componente curricular de Química, em que participaram 20 estudantes do Ensino Médio de uma escola pública do Rio Grande do Sul. A investigação ocorreu no âmbito de uma atividade que utilizou como procedimento didático a Pesquisa em Sala de Aula. Os dados foram coletados mediante instrumentais aplicados no início e no final da atividade, tratados por meio da Análise textual discursiva. As categorias emergentes da análise indicam que a inserção das perguntas dos discentes em propostas didáticas envolvendo a pesquisa perpassa a compreensão de que o estudante é um sujeito capaz de protagonizar sua aprendizagem e elaborar novos saberes a partir do que já conhece, além de dar sentido ao que é estudado na escola. Por fim, evidencia-se que, mais do que apenas esclarecer dúvidas, as perguntas dos estudantes têm o potencial de auxiliar o professor na organização e na realização do ensino de Química.

Palavras-chave: Perguntas dos estudantes; Pesquisa em Sala de Aula; aprendizagem de Química.

Resumen: Este estudio de enfoque cualitativo tiene como objetivo responder a la siguiente pregunta: ¿cómo pueden las preguntas sobre combustibles, propuestas por los estudiantes, contribuir al aprendizaje de la Química Orgánica? Esta investigación, con enfoque cualitativo, se realizó en el contexto del componente curricular de la Química, en la que participaron 20 estudiantes de secundaria de una escuela pública de Río Grande do Sul. La investigación tuvo lugar en el contexto de una actividad que utilizaba la investigación en el aula como procedimiento de enseñanza. Los datos se recogieron mediante instrumentos aplicados al principio y al final de la actividad, tratados mediante análisis textual discursivo. Las categorías de análisis emergentes indican que la inserción de las preguntas de los estudiantes en las propuestas didácticas que implican la investigación impregna la comprensión de que el estudiante es un sujeto capaz de dirigir su aprendizaje y elaborar nuevos conocimientos a partir de lo que ya sabe, además de dar sentido a lo que se estudia en la escuela. Por último, es evidente que, más que aclarar dudas, las preguntas de los estudiantes tienen el potencial de ayudar al profesor en la organización y realización de la enseñanza de la química. 
Palabras clave: Preguntas de los estudiantes; investigación en el aula; aprendizaje de la química.

\section{INTRODUÇÃO}

As abordagens pedagógicas representam ferramentas para desenvolver capacidades que possibilitem a inserção dos estudantes em uma sociedade pautada por constantes transformações e desafios cada vez mais complexos que exigem autonomia e criatividade. Os conteúdos escolares, portanto, não se constituem um fim em si mesmo, mas sim, instrumentos que irão auxiliar os estudantes a atuar de modo autônomo e criativo em seus contextos. Porém, o modo como os conhecimentos escolares estão organizados parecem não favorecer os estudantes, especialmente por se encontrarem distantes das suas demandas (LIMA; GRILLO, 2008). Uma pesquisa coletou perguntas de estudantes referentes ao componente curricular de Biologia que, posteriormente, foram comparadas com os programas escolares, o resultado mostrou que mais de $60 \%$ das perguntas não poderiam ser respondidas por meio dos conteúdos programáticos (HAGAY; BARAM-TSABARI, 2011). No que diz respeito aos conteúdos relativos ao componente curricular de Química, é comum que estes tenham seu foco em nomenclaturas, classificações e teorias, por exemplo, tornando o aprendizado maçante e descontextualizado, gerando desinteresse em aprender.

A falta de interesse dos estudantes em aprender especialmente assuntos relacionados à Ciências e áreas correlatas, como a Química parece ter impacto em avaliações internacionais como PISA $^{1}$ (Programme for Internacioanl Student Assessment). No que diz respeito a esta área do conhecimento os resultados da avaliação de 2018 (BRASIL, 2019) destacam que o maior número, ou seja 31,4\%, dos 10.691 estudantes brasileiros que participaram da avaliação, estão no nível de proficiência em Ciências $1 \mathrm{a}^{2}$. Neste nível, estão aptos a utilizar conhecimentos factuais e procedimentais incipientes ou o próprio cotidiano para dar conta de explicações relativas a eventos científicos básicos. Também, conseguem estabelecer conexões simples e decodificar dados representados graficamente que demandam baixo nível cognitivo. Este resultado, indica a fragilidade dos conhecimentos científicos dos estudantes brasileiros nesta área.

\footnotetext{
${ }^{1}$ O Programa de Avaliação Internacional de Alunos (PISA) é uma pesquisa trienal com alunos de 15 anos de idade que avalia até que ponto eles adquiriram os principais conhecimentos e habilidades essenciais para a plena participação em sociedade.

${ }^{2}$ Os níveis em ordem crescente são $1 \mathrm{~b}, 1 \mathrm{a}, 2,3,4,5$ e 6.
}

Recebido em: $01 / 09 / 2020$

Aceito em: $27 / 10 / 2020$ 
Como as ações pedagógicas podem mobilizar o aprendizado dos estudantes em

Química? De que modo é possível desenvolver capacidades que lhes permitam atuar em uma sociedade que, mais do que respostas prontas, necessita reelaborar perguntas e construir respostas novas? Neste sentido o incentivo ao protagonismo dos estudantes é relevante e carece ser estimulado, de modo constante, por meio da problematização de eventos cotidianos, bem como, de seu contexto social. É a voz dos estudantes que deve reverberar no âmbito da sala de aula, pois é, a partir dela, que se pode conhecer entre outras informações, os anseios, os conhecimentos, as fragilidades, os pensamentos e as dúvidas dos estudantes, para que então o professor possa organizar as suas ações pedagógicas de modo produtivo. Ira Shor (FREIRE; SHOR, 1992, p.20) em diálogo como Paulo Freire destaca para a relevância em dar voz aos estudantes: “[...] se não leio a autêntica linguagem- pensamento deles, sinto-me prejudicado por não poder pesquisar sobre seus assuntos e seus níveis de desenvolvimento".

As Diretrizes Curriculares Nacionais da Educação Básica (DCNEB) (BRASIL, 2013) validaram a pesquisa como princípio pedagógico, o que implica em estruturar mudanças que transformem a sala de aula, valorizando a investigação como uma maneira de aprender e ensinar. Nela, professores e estudantes atuam colaborativamente na construção do conhecimento (DEMO, 2015), edificando o processo de autonomia dos envolvidos, permitindo o desenvolvimento da autogestão do conhecimento, da criticidade e da proatividade, entre outras capacidades. Isto decorre do caráter emancipatório da pesquisa, que busca instrumentalizar seus participantes a questionarem seu entorno, desconstruindo verdades até então prontas de modo autônomo. Apoiada nos pressupostos do Educar pela Pesquisa, a Pesquisa em Sala de Aula busca sistematizar esta prática no âmbito escolar (MORAES; GALIAZZI; RAMOS, 2012) compreendendo que a realidade não representa algo acabado, mas sim objeto da construção humana. A pesquisa em sala de sula está organizada a partir de um ciclo dialético que compreende: o questionamento, a construção de argumentos e a comunicação.

Considerando o questionamento, o ponto de partida da pesquisa em sala de sula, é inegável que o próprio estudante se envolva neste processo expressando suas dúvidas e interesses por meio de perguntas (FREIRE; FAUNDEZ, 2011). Mais do que uma simples sondagem, é interessante que as perguntas sejam a matéria prima para o planejamento e desenvolvimento da ação pedagógica. Não se trata aqui, de fazer valer 
apenas o que o estudante "quer" aprender, mas que ocorra uma aproximação dos conhecimentos sistematizados e os interesses, de modo a colocar o estudante como centro de sua aprendizagem (HAGAY; BARAM-TSABARI, 2011). Diante disto, este estudo se justifica pela necessidade de implementar ações que valorizem as perguntas dos estudantes, estimulando estes a construírem e reconstruírem o seu próprio conhecimento por meio da pesquisa, especialmente em Química, componente curricular que permeia os diversos contexto em que o estudante interage.

Considerando o que foi exposto, este artigo tem como objetivo compreender de que modo perguntas dos estudantes sobre combustiveis, podem contribuir para a aprendizagem de Química Orgânica. Incialmente, é discutida a pesquisa como princípio pedagógico e as etapas da Pesquisa em Sala de Aula, posteriormente, é apresentado o percurso metodológico, os resultados e considerações finais.

\section{PESQUISA COMO PRINCÍPIO EDUCATIVO PEDAGÓgICO E AS PERGUNTAS DOS ESTUDANTES}

A produção exponencial de conhecimento, característica do tempo presente, impõem a escola o desafio de socializar estes novos conhecimentos de modo a ampliar o nível global da educação. Pode-se destacar que as novas tecnologias, têm impactado a escola, e repercutem de modo direto nas estratégia a serem empregadas, bem como, em relação aos elementos envolvidos no processo, modificando os papéis da escola, dos professores, dos estudantes, das estratégias, dos recursos e dos instrumentos avaliativos (BRASIL, 2013).

A escola deixa de ser valorizada como único espaço de geração de conhecimento, sendo agregada a ela outras instituições, movimentos e atividades culturais, públicas ou privadas, bem como, os meios de comunicação. Diante da relevância dos novos mecanismos de consumo e informação, a escola assume o papel de destaque, no sentido de converter as informações que os próprios estudantes se apropriaram ao longo de suas vivências em conhecimento sistematizado.

A sociedade de informação requer dos seus participantes um aprendizado que se estenda por toda a vida, portanto além da mera informação ou capacidade para realizar uma determinada atividade, é notória a ampliação da capacidade de aprender a aprender. $\mathrm{Na}$ atualidade, não se aprende tudo, para depois nos integrarmos socialmente. O 
aprendizado se dá na busca das respostas dos problemas atuais, na significação da experiência (CONSTANTINO et al., 2019)

Neste sentido, Demo (2012), aponta para o desenvolvimento de estratégia que permitam manejar e produzir conhecimento em permanente aprimoramento. A conduta do professor diante deste cenário em constante mudança, deixa de ser transmissiva e passa a ser mediativa, fomentando a pesquisa, a elaboração de conhecimento e a valorização de atividade colaborativas. Para tanto, a problematização dos interesses dos estudantes pode nortear o planejamento das aulas, de modo colaborativo, priorizando a aprendizagem pela pesquisa e as interações sociais entre os envolvidos (KIEREPKA; ZANON, 2019)

As DCNEB (BRASIL, 2013), legitimaram a pesquisa como princípio pedagógico em todas as etapas da educação considerando que ela pode estimular a curiosidade, promover inquietação, instigar o protagonismo dos estudantes na busca pelo conhecimento nas mais variadas fontes, entre outras possibilidades. O documento também expressa que a própria inquietude frente a realidade fomenta a pesquisa, à medida que colabora para que os estudantes possam individualmente ou em grupos proporem perguntas e construírem respostas por meio das ferramentas disponíveis (livros, internet, entrevistas, entre outros) de modo independente num processo de elaboração e reelaboração do próprio conhecimento.

Embora as DCNEB (BRASIL, 2013), use a terminologia de pesquisa como princípio pedagógico, esse estudo utilizará uma terminologia mais atual, que é Pesquisa como Princípio Educativo (PAULETTI, 2018). Haja visto que, o termo educativo, que deriva de educação, é mais amplo que o termo pedagógico. Uma vez que educação, é algo que ultrapassa o espaço escolar, é um meio de inserir os estudantes na sociedade. A Pesquisa como Princípio Educativo é uma forma de aprendizagem que contempla professores, estudantes, comunidade escolar e aborda questões sociais, políticas, econômicas e ambientais (PAULETTI, 2018).

A pesquisa quando compreendida como princípio educativo representa um modo de aprender e também e ensinar. A relação verticalizada do processo de ensino e aprendizagem é superada e, o professor e o estudantes passam a atuar como parceiros do processo, colaborando com os conhecimentos e capacidades que edificaram ao longo de sua trajetória. O exercício da pesquisa no âmbito da escolar extrapola a pesquisa 
científica formalizada, proporciona o desenvolvimento de atitudes científicas como a interpretação, a análise, a criticidade, a reflexão, a criatividade, o levantamento de soluções e alternativas, entre outras, capazes de munir os atores no processo a continuarem a aprender (BRASIL, 2013).

Demo (2015) em sua proposta "Educar pela Pesquisa" apresenta pressupostos norteadores da pesquisa no âmbito escolar. O autor compreende que a educação pela pesquisa, como característica inerente da própria educação, no que diz respeito ao espaço escolar e acadêmico; reconhece o questionamento reconstrutivo como base dos processos investigativos; expressa a imperatividade de que a pesquisa seja vivenciada de modo cotidiano por professores e estudantes e, define a educação como um processo que permite a ser humano fazer e refazer-se constantemente na sua relação com seu entorno.

A Pesquisa em Sala de Aula (MORAES; GALIAZZI; RAMOS, 2012) pode representar um modo de vivenciar na prática os pressupostos do Educar pela Pesquisa apontados por Demo (2015). Ela representa um modo de incluir professores e estudantes, numa dinâmica dialética em espiral, que tem como ponto de partida o questionamento “[...] dos estados do ser, fazer e conhecer [...]” (MORAES; GALIAZZI; RAMOS, 2012, p. 12). Os novos estágios do ser, fazer e conhecer atingidos, são então comunicados aos participantes para apreciação e validação, passando a fazer parte do discurso. A Pesquisa em Sala de Aula extrapola a pesquisa com viés acadêmico pela sua flexibilidade e público e tem como momentos estruturantes: o questionamento, a construção de argumentos e a comunicação.

Considerando a pesquisa como um modo de aprender e ensinar, o questionamento é o ponto de partida da novos entendimentos, sendo assim promove a complexificação do que se conhece. Barreiro (2012, p. 135) compreende que a pesquisa está vinculada ao caráter questionador de modo que não pode ocorrer pesquisa amparada na concepção de que o conhecimento pode simplesmente ser adquirido, “[...], mas de questioná-lo e assim reconstruí-lo”. A Pesquisa em Sala de Aula apresenta-se como uma maneira significativa para que o questionamento seja empregado cotidianamente. No que diz respeito ao ensino e aprendizagem de Química o questionamento permite valorizar contextos relevantes para os estudantes, estabelecendo intercâmbio entre o entorno e os conhecimentos científicos sistematizados. 
O questionamento representa a alavanca propulsora da Pesquisa em Sala de Aula, pois a investigação tem como ponto de partida uma ou mais perguntas que representam dúvidas que carecem de respostas. No âmbito da sala de aula, o questionamento pode partir tanto de professores quanto de estudantes, porém vários autores (DEMO, 2015; CHIN; OSBORNE, 2008; FEIRE; FAUNDEZ, 2011; MORAES; GALIAZZI; RAMOS, 2012) enfatizam que ao partir das indagações manifestadas pelos estudantes há a possibilidade de promover uma o maior envolvimento e empenho destes nas atividades escolares.

Para Wertsch (1999), as perguntas geradas pelos estudantes expressam além dos conhecimentos já elaborados sobre os conceitos científicos, os interesses em relação a determinado tema e seu envolvimento, no ato de perguntar. Desse modo é inegável a relevância das perguntas dos estudantes, para o seu aprimoramento intelectual, especialmente, na orientação das aulas de Química em função dos interesses presentes em suas indagações. As perguntas devem ser constantemente estimuladas, de modo a estabelecer um ambiente de ensino, em que os estudantes se sintam representados tanto pelos conhecimentos já edificados, quanto pelos seus interesses. Chin e Osborne (2008), atestam que as perguntas geradas pelos estudantes podem fornecer informações relevantes para o trabalho professor, permitindo a reflexão e o aperfeiçoamento sua prática.

Não basta apenas levantar dúvidas, é necessário avançar na busca na elaboração de respostas. Sendo assim, a elaboração de argumentos representa o segundo momento da Pesquisa em Sala de Aula (MORAES; GALIAZZI; RAMOS, 2012). Um argumento representa o conjunto de proposições, que são utilizadas para explicar ou rejeitar uma determinada ideia. Ao desenvolver a aptidão argumentativa os estudantes passam a assumir a responsabilidade com seu próprio aprendizado (RAMOS, 2012). Para a elaboração de argumentos, o estudante pode realizar experimentos, consultar livros e a internet, entrevistar pessoas da comunidade e outros professores que possam auxiliar na construção das respostas. Cabe ressaltar a relevância do professor, tanto no refino das perguntas elaboradas pelos estudantes, quanto na indicação e orientação de fontes confiáveis para a consulta (BRASIL, 2013).

A comunicação é o momento da Pesquisa em Sala de Aula em que os argumentos edificados são apresentados para a validação por meio da crítica e da discussão, fato que reforça as elaborações do momento anterior. Para Moraes; Galiazzi e 
Ramos (2012) é na multiplicidade de perspectivas que os argumentos podem ser aperfeiçoados e consolidados. Os autores recomendam que este momento envolva inicialmente grupos menores e se estenda para grupos mais amplos, sempre privilegiando os questionamentos e colaborações gerados nas discussões. Tais contribuições, permitem que os argumentos sejam então refinados, e passem a constituir um novo conhecimento.

Vale ressaltar que os momentos da Pesquisa em Sala de Aula constituem um ciclo dialético, como expresso na Figura 1. Este ciclo, pode ser acionado em qualquer uma das etapas, ao promover novos questionamentos, permite a elaboração de argumentos e novas comunicações, assim, promover ampliação do ser, saber e fazer.

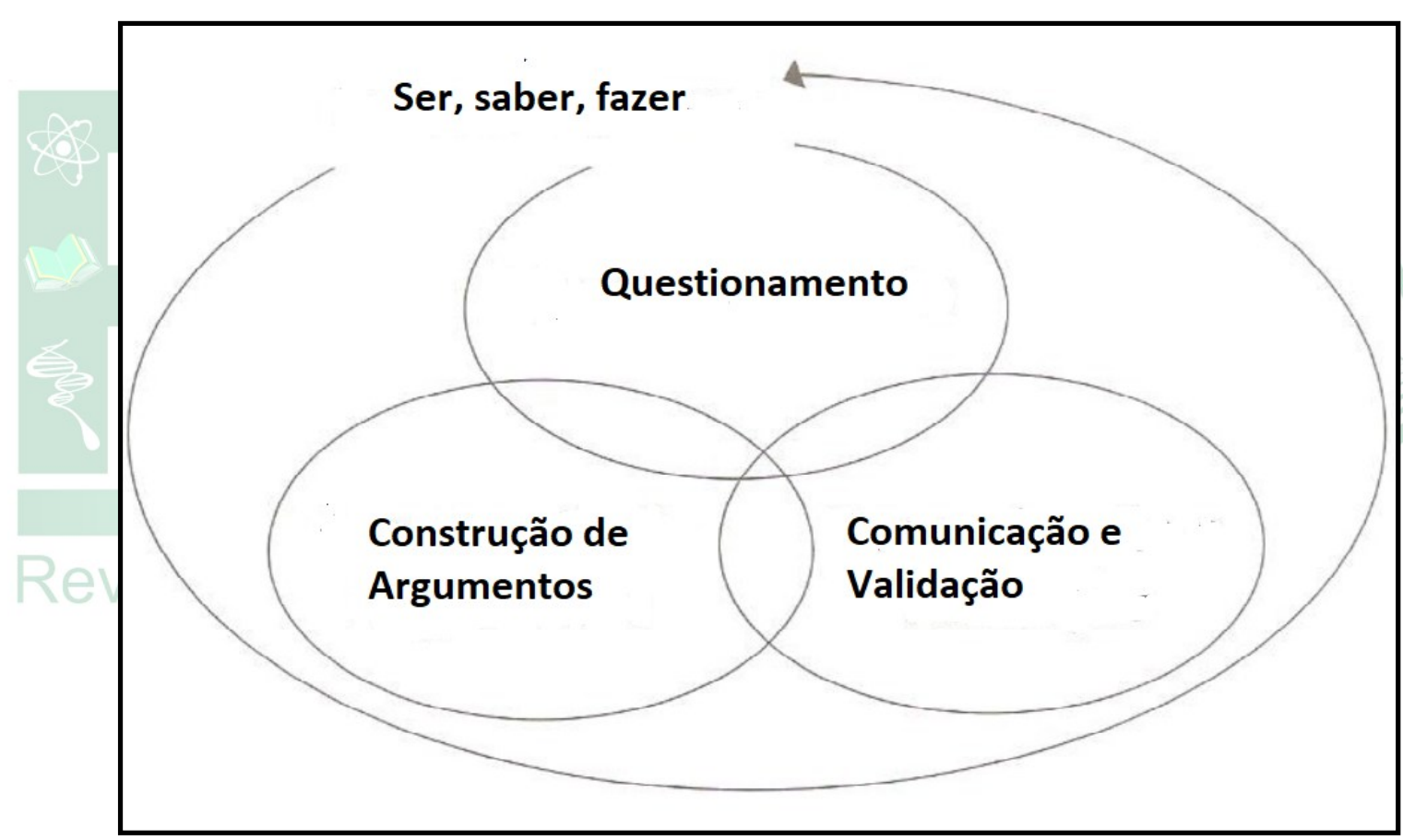

Figura 1: Ciclo Dialético da Pesquisa em Sala de Aula (MORAES, 2012, p. 67.).

Por tudo o que foi apontado, entende-se que a pesquisa quando compreendida como princípio educativo, pode ser explorado nos mais diferentes componentes curriculares e etapas educativas. Neste estudo, se apresenta a sua inserção no âmbito do ensino e da aprendizagem de Química no $3^{\circ}$ Ano do Ensino Médio, tendo como base as perguntas propostas pelos estudantes em relação a temática combustíveis.

\section{PROCEDIMENTOS METODOLÓGICOS}

Esta pesquisa tem abordagem qualitativa conforme Bogdan e Biklen (1994). Este método de pesquisa considera o ambiente natural como a fonte direta de dados e os 
pesquisadores como instrumentos principais. Os dados são examinados numa perspectiva fenomenológica da realidade (BICUDO, 2011), o que implica o estabelecimento de relação entre o fenômeno em questão e a percepção, de modo que o pesquisador compreenda as características do objeto de estudo. Não há o intuito de promover generalizações, porém priorizam-se considerações alicerçadas entre as articulações elaboradas e o significado que é manifestado pelos sujeitos.

A investigação que trata este estudo foi efetuada no contexto do componente curricular de Química, com a participação de 20 estudantes do $3^{\circ}$ ano do Ensino Médio de uma escola pública no Vale dos Sinos, Rio Grande do Sul, Brasil. Para garantir o anonimato dos participantes, os estudantes foram designados por meio da letra maiúscula $\mathrm{P}$, seguido de números do 1 ao 20. Sua ocorrência se deu no âmbito de uma atividade que utilizou como procedimento didático a Pesquisa em Sala de Aula (MORAES; GALIAZZI; RAMOS, 2012) que foi organizada em oito encontros de 90 minutos cada um. Os dados foram coletados mediante instrumentais aplicados aos participantes no início, contendo a questão: Quais são os seus conhecimentos sobre os combustíveis em relação a sua composição, produção e aplicação?; e no final da atividade, com o questionamento: O que você aprendeu sobre os combustíveis em relação a sua composição, produção e aplicação?. As respostas dos estudantes aos instrumentais foram tratadas por meio da Análise textual discursiva (ATD) (MORAES; GALIAZZI, 2016). Esta ferramenta de análise compreende três etapas: a unitarização, $a$ categorização e a elaboração de metatextos. A unitarização compreende o momento em que o todo é desmembrado em unidades de significado, momento que se caracteriza pela desconstrução do corpus. Na sequência, são estabelecidas relações entre as unidades de significado, processo que tem como especificidade a produção de uma nova ordem. Nesta etapa são organizadas categorias primárias, secundárias, até que se alcance as macro categorias, etapa que é denominada de categorização. Finalmente são elaborados textos renovados que expressam as novas compreensões atingidas a partir da categorização: os metatextos. Trata-se de um processo auto organizado.

As ações desenvolvidas durante esta intervenção, iniciaram a partir de uma breve explanação por parte da professora de Química da turma e pesquisadora, sobre a temática combustiveis. Na sequência, os estudantes puderam propor, por escrito, perguntas de seu interesse sobre o assunto. Sendo geradas 76 perguntas que posteriormente foram agrupadas pela semelhança de demandas expressas, de modo 
coletivo, sob orientação da professora, resultando em sete tópicos: i) impactos ambientais dos combustíveis; ii) tipos de combustíveis; iii) combustíveis renováveis; iv) combustíveis não renováveis; v) composição e produção de combustíveis, vi) reação de combustão, e vii) petróleo, conforme mostra o Quadro 1.

Quadro 1: Classificação das perguntas dos estudantes por temas

\begin{tabular}{|c|c|c|}
\hline Temas & $\begin{array}{c}\text { Total de } \\
\text { perguntas }\end{array}$ & Exemplo de perguntas \\
\hline $\begin{array}{l}\text { Impactos ambientais dos } \\
\text { combustíveis }\end{array}$ & 20 & $\begin{array}{l}\text { Quais as consequências para o meio ambiente com o } \\
\text { uso dos combustíveis? } \\
\text { Qual é o combustível fóssil menos poluente? }\end{array}$ \\
\hline Tipos de combustíveis & 16 & $\begin{array}{l}\text { Existem diferenças entre os combustíveis para } \\
\text { automóveis, terrestres ou aéreos? } \\
\text { Quais são os tipos de combustíveis disponíveis no } \\
\text { mercado brasileiro? }\end{array}$ \\
\hline Combustíveis renováveis & 11 & $\begin{array}{l}\text { É possível criar combustíveis à base de plantas? } \\
\text { O que é biocombustível? }\end{array}$ \\
\hline $\begin{array}{l}\text { Combustíveis não } \\
\text { renováveis }\end{array}$ & 10 & $\begin{array}{l}\text { Por que a gasolina é extremamente inflamável? } \\
\text { O que são combustíveis fósseis? }\end{array}$ \\
\hline $\begin{array}{l}\text { Composição e produção } \\
\text { de combustíveis }\end{array}$ & 9 & $\begin{array}{l}\text { Como o combustível é produzido? } \\
\text { Qual a composição do combustível? }\end{array}$ \\
\hline Reação de combustão & 8 & $\begin{array}{c}\text { Por que algumas reações de combustão liberam } \\
\text { monóxido de carbono? } \\
\text { Por que a combustão ocorre? }\end{array}$ \\
\hline Petróleo & 2 & $\begin{array}{c}\text { O que é petróleo? } \\
\text { Como ocorreu o processo de formação do petróleo? }\end{array}$ \\
\hline Hist Total & 10 & -- \\
\hline
\end{tabular}

Fonte: As autoras, 2020.

Posteriormente, os estudantes receberam um instrumental e foram orientados pela professora a elencar, por escrito, seus conhecimentos sobre composição e produção de combustíveis. Na aula seguinte, a professora organizou a turma em grupos de estudo e, solicitou que cada um destes escolhesse um dos tópicos da classificação de perguntas. Explicou aos grupos, que deveriam elaborar um trabalho por escrito com as respostas às perguntas do tópico selecionado, para posterior socialização na turma. Nos três encontros seguintes, os estudantes trabalharam em grupos, orientados pela professora, no laboratório de informática, para realizar consultas na internet e organizar a apresentação dos temas em slides. Nos dois encontros posteriores, os grupos compartilharam seus trabalhos com os colegas, situação que proporcionou participação dos estudantes com questionamentos e reflexões. Na aula seguinte, realizou-se uma avalição conjunta da atividade, coletando-se sugestões para seu aprimoramento, neste 
momento, a professora também aplicou o instrumental final, em que os estudantes deveriam novamente, elencar seus entendimentos sobre composição e produção de combustíveis, considerando os conhecimentos edificados a partir dos estudos socializados.

\section{RESULTADOS E DISCUSSÕES}

Nessa seção, apresentam-se os resultados do estudo obtido através da análise do instrumental inicial e final. Destaca-se que as perguntas dos estudantes serviram para auxiliar o professor a desenvolver o ensino de Química, com base nos interesses dos estudantes em aprender, manifestados por meio das perguntas. Desse modo, as perguntas dos estudantes não foram objeto de análise.

\subsection{Análise do instrumental inicial}

As respostas ao instrumental inicial: Quais são os seus conhecimentos sobre os combustíveis em relação a sua composição, produção e aplicação? foram elaboradas por 20 estudantes, geraram 30 unidades de sentido, as quais deram origem às categorias emergentes descritas no quadro a seguir.

Quadro 2: Categorização das respostas ao instrumental inicial
\begin{tabular}{|c|c|}
\hline Categoria & Unidades de Sentido (US) \\
\hline Aplicação dos combustíveis & 13 \\
\hline Combustíveis estão relacionados com o petróleo & 10 \\
\hline Existem diferentes tipos de combustíveis & 5 \\
\hline Impacto ambiental causado pelos combustíveis & 2 \\
\hline Total & 30 \\
\hline
\end{tabular}

Fonte: As autoras, 2020.

As respostas da questão inicial revelaram os conhecimentos prévios ou iniciais que os estudantes possuíam sobre o tema, os quais podem indicar seus domínios conceituais. Em relação à categoria Aplicação dos combustíveis os estudantes demonstraram conhecimento de que os combustíveis produzem energia, que pode servir para acionar motores de veículos e para garantir o funcionamento de máquinas.

Referente à categoria Combustíveis estão relacionados com o petróleo, alguns estudantes afirmaram que os combustíveis são produzidos a partir do petróleo, como mostra o enunciado "Sobre a composição sei apenas dos fósseis que vem do petróleo" (P9). No entanto, não explicaram como os combustíveis são produzidos a partir do 
petróleo. Ainda, outros estudantes afirmaram que os combustíveis são compostos por petróleo. Isso mostra o desconhecimento que alguns estudantes tinham em relação à composição dos combustíveis.

Em relação à categoria, Existem diferentes tipos de combustíveis, os estudantes mencionaram a gasolina, diesel e o álcool. Esse último, foi o mais citado pelos estudantes.

Sobre a categoria Impacto ambiental causado pelos combustíveis, os enunciados revelaram que os estudantes demonstraram conhecimento de que os combustíveis causam impacto ambiental, porém não descrevem o modo como isso ocorre, como mostra o enunciado "A maioria dos combustíveis que utilizamos agridem a natureza e prejudicam a nossa saúde" (P3).

\subsection{Análise do instrumental final}

As respostas ao instrumental final: O que você aprendeu sobre os combustíveis em relação a sua composição, produção e aplicação? elaboradas por 20 estudantes, geraram 73 unidades de sentido, as quais originaram sete categorias emergentes apresentadas no quadro a seguir.

Quadro 3: Categorização das respostas ao instrumental final

\begin{tabular}{|c|c|}
\hline Categoria & Unidades de Sentido (US) \\
\hline Sta $\mid$ Combustíveis não-renováveis & 21 \\
\hline Combustíveis renováveis & 15 \\
\hline Impacto ambiental causado pelos combustíveis & 12 \\
\hline Gasolina & 9 \\
\hline Reação de combustão & 6 \\
\hline Composição e propriedades dos combustíveis & 6 \\
\hline Aplicação dos combustíveis & 4 \\
\hline Total & 73 \\
\hline
\end{tabular}

Fonte: As autoras, 2020.

Referente à categoria Combustíveis não-renováveis, os estudantes mencionaram que esses combustíveis são derivados de fontes não renováveis como o carvão, o gás natural e o petróleo, os quais se originaram pela fossilização de matéria orgânica. Ainda, os combustíveis nucleares foram mencionados, como mostra o enunciado: “Combustíveis nucleares são obtidos a partir do processo de fissão nuclear de átomos de urânio, um minério esgotável de energia. Quando ocorre a fissão no núcleo desse 
material, libera-se uma grande quantidade de energia, que é utilizada para a produção de eletricidade" (P3). Embora o estudante demonstre um conhecimento significativo sobre fontes não-renováveis, seu enunciado trata de um minério inorgânico e o foco da proposta é a aprendizagem de Química Orgânica. Contudo, não devemos desprezar tal questionamento, haja visto que, é um assunto pertinente para o ensino de Química.

$\mathrm{Na}$ categoria Combustiveis Renováveis, os estudantes afirmaram que esses combustíveis são produzidos a partir de fontes inesgotáveis, como mostra o enunciado: "[...] são fabricados com substâncias que se renovam na natureza, como: energia solar, eólica, biomassa, hidrogênio, etc.” (P3).

Em relação à categoria Impacto ambiental, causado pelos combustíveis, os estudantes mencionaram que o etanol é o combustível menos poluente, que os combustíveis fósseis poluem mais que os renováveis e que, a emissão de gases poluentes pode contribuir para o efeito estufa. Como mostra a resposta "Os combustíveis são prejudicais tanto para o ser humano como para o meio ambiente. Por exemplo, a emissão de gases poluentes na atmosfera aumentando o efeito estufa" (P18). Essa categoria, mostrou que os estudantes ampliaram a sua compreensão sobre o modo como os combustíveis causam impacto ambiental e os modos de minimizar esse impacto.

Na categoria Gasolina, os estudantes afirmaram que a gasolina é uma mistura de hidrocarbonetos e, por esse motivo, não apresenta uma fórmula definida, que existem vários tipos de gasolina utilizados no Brasil, como afirma o enunciado: "Existem 4 tipos de gasolina: comum, aditivada, premium e podium" (P8). Os estudantes também, destacaram que a gasolina apresenta riscos à saúde por conter benzeno, substância química cancerígena.

Referente à categoria Reação de combustão, os estudantes manifestaram conhecimento de que os combustíveis são substâncias que sofrem combustão e souberam explicar o modo como essa reação ocorre, como mostra o enunciado: "A combustão é ocasionado pela energia gerada por um combustível e um comburente, no caso, é necessário um “gatilho" para que possa ocorrer a combustão” (P8).

Sobre a categoria Composição e propriedades dos combustíveis os estudantes mencionaram que os combustíveis são todas as substâncias que podem ser queimadas para produzir energia, podem ser encontrados nos três estados físicos da matéria e que 
os combustíveis apresentam propriedades específicas, como o ponto de fulgor. Conforme mostra o enunciado: "Ponto de fulgor, quanto menor maior a chance de fogo" (P12). Na sua resposta o estudante relacionou o ponto de fulgor com a possibilidade de os combustíveis iniciarem a combustão. No seu entendimento, quanto menor o ponto de fulgor do combustível, maior a probabilidade deste propagar uma chama ao entrar em contato com uma fonte de ignição. Isso mostra, que os estudantes começaram a se apropriar dos conceitos específicos relacionados a esse tema, como o ponto de fulgor.

Sobre a categoria Aplicação dos combustiveis, os estudantes afirmaram que os combustíveis servem para gerar energia capaz de garantir o funcionamento de motores de veículos e máquinas, como mostra o enunciado: "Os combustíveis geralmente são utilizados para obter energia e movimentar automóveis, aviões, máquinas industriais, etc.” (P18).

\subsection{Possíveis articulações entre as categorias de análise}

Com base nas respostas dos estudantes ao instrumental inicial, é possível afirmar que os conhecimentos iniciais dos estudantes em relação aos combustíveis eram superficiais e estavam relacionados ao seu cotidiano, como os tipos de combustíveis e as suas aplicações. O Quadro 4 apresenta a comparação entre as categorias emergentes no instrumental inicial e final.

Quadro 4: Comparação entre as categorias emergentes no instrumental inicial e final

\begin{tabular}{|l|c|l|c|}
\hline Categoria - Instrumental Inicial & US & Categoria - Instrumental Inicial & US \\
\hline Aplicação dos combustíveis & 13 & Combustíveis não-renováveis & 21 \\
\hline $\begin{array}{l}\text { Combustíveis estão relacionados } \\
\text { com petróleo }\end{array}$ & 10 & Combustíveis renováveis & 15 \\
\hline $\begin{array}{l}\text { Existem diferentes tipos de } \\
\text { combustíveis }\end{array}$ & 5 & $\begin{array}{l}\text { Impacto ambiental causado pelos } \\
\text { combustíveis }\end{array}$ & 9 \\
\hline $\begin{array}{l}\text { Impacto ambiental causado pelos } \\
\text { combustíveis }\end{array}$ & 2 & Gasolina & 6 \\
\hline- & - & Reação de combustão & 6 \\
\hline- & - & Aplicação dos combustíveis & 4 \\
\hline- & $\mathbf{3 0}$ & Total & $\mathbf{7 3}$ \\
\hline
\end{tabular}

Fonte: As autoras, 2020. 
Pode-se constatar que o número de categorias emergentes e de unidades de sentido foi maior no instrumental final. A categoria Impacto ambiental causado pelos combustíveis emergiu nos dois instrumentos. No entanto, no instrumental final o número de unidades de sentido aumentou. Isso demonstra que os estudantes foram capazes de falar mais sobre assunto e, desse modo, puderam ter novas compreensões. Sobre esse tema, os estudantes propuseram o maior número de perguntas. Para Souza (2006, p.111) “As perguntas dos alunos abrem uma oportunidade perfeita para ensinar, bem como para aprender. Cada vez que o aluno ousa questionar a sua mente abre-se para a aprendizagem e esta é uma abertura perfeita para o ensino". O fato de os estudantes formularem muitas perguntas sobre o impacto ambiental causado pelos combustíveis demonstra que eles tinham interesses em relação a esse tema e, com o desenvolvimento da Pesquisa em Sala de Aula, tiveram a oportunidade de construir conhecimentos sobre essa temática.

A categoria Aplicação dos combustiveis emergiu na análise do instrumental inicial com 13 unidades de sentido, e final com 4 unidades de sentido. Isso mostra que antes da atividade desenvolvida, a ideia que os estudantes tinham de que combustível produz energia estava relacionado as suas vivências como a utilização de combustível num automóvel. Após o estudo dos combustíveis, os estudantes adquiriram novos conhecimentos sobre o tema e foram capazes de expressar esses conhecimentos, o que aumentou o número de categorias de análise.

Também no início do trabalho, na categoria Combustíveis estão relacionados com o petróleo, alguns estudantes afirmaram que os combustíveis são produzidos a partir do petróleo, outros mencionaram que os combustíveis são compostos por petróleo. No final do trabalho, os estudantes ampliaram seus conhecimentos sobre a relação do petróleo com os combustíveis, isso é evidenciado por meio das categorias que emergiram no instrumental final: Combustíveis não-renováveis, Combustíveis renováveis, Gasolina, Reação de combustão.

$\mathrm{Na}$ categoria emergente do instrumental inicial, Existem diferentes tipos de combustíveis, os estudantes apenas mencionaram os combustíveis utilizados no Brasil, como a gasolina, o álcool e o diesel. Já no instrumental final as compreensões sobre os diferentes tipos de combustíveis emergiram nas categorias Composição e propriedades dos combustiveis e Gasolina. 
$\mathrm{O}$ aumento do número de categorias emergentes e de unidades de sentido no instrumental final pode ser indicativo que a percepção dos estudantes sobre os conceitos relacionados ao tema tornou-se mais complexa. Isso ratifica a valorização das perguntas dos estudantes e o desenvolvimento da Pesquisa em Sala de Aula no ensino de Química. Conforme Bargalló e Tort (2006, p. 65, (tradução nossa) a aprendizagem é descrita como "[...] a interação entre os significados do professor e de seus alunos, de modo que o que cada um aprende é em parte compartilhado e em parte único”. Nesse sentido, a atividade possibilitou essa interação, o que pode auxiliar na aprendizagem dos estudantes.

\section{CONSIDERAÇÕES FINAIS}

Esse estudo aponta como resultados significativos, que a atividade proposta permitiu a apropriação da temática combustíveis, sendo elencados como principais resultados:

i) Os estudantes puderam expressar seus interesses e aprofundar seus conhecimentos iniciais. Isso foi evidenciado pelas categorias emergentes a partir da análise do instrumental inicial e final.

ii) Com a escrita das perguntas e produção do texto, na leitura e na troca de conhecimentos entre estudantes e a professora, nas etapas de argumentação e comunicação, os intercâmbios discursivos possibilitaram a reconstituição do conhecimento químico, bem como ampliar conteúdos conceituais, procedimentais e atitudinais.

iii) A inserção das perguntas dos discentes, em propostas didáticas, que envolvam a pesquisa, perpassa a compreensão de que o estudante é um sujeito capaz de protagonizar sua aprendizagem e elaborar novos saberes a partir do que já conhece, além de dar sentido ao que é estudado na escola.

iv) Por fim, evidencia-se que, mais do que apenas esclarecer dúvidas, as perguntas dos estudantes têm o potencial de auxiliar o professor na organização e na realização do ensino de Química.

Diante dos resultados sugere-se que sejam difundidos os momentos do ciclo dialético da Pesquisa em Sala de Aula, com ênfase na formação de professores dos 
diferentes campos do conhecimento. Acredita-se que tal ação possa contribuir na superação do arranjo convencional dos conhecimentos escolares, possibilitando o desenvolvimento de estudantes e professores como agentes históricos do processo de ensino e aprendizagem.

\section{REFERÊNCIAS}

BARGALlÓ, C. M.; TORT, M. R. Plantear preguntas: un punto de partida para aprender ciências. Revista Educación y Pedagogía, v.18, n. 45, p. 63-71, may./ago., 2006.

BARREIRO, Cristhianny Bento. Questionamento sistematizador: alicerce da reconstrução. In: MORAES, Roque; LIMA, Valderez Marina do Rosário (org.).

Pesquisa em sala de aula: tendências para a educação em novos tempos. Porto Alegre: EDIPUCRS, p.127-140, 2012.

BICUDO. Maria Aparecida Viggiani. Pesquisa qualitativa: segundo a visão fenomenológica. São Paulo: Cortez, 2011.

BOGDAN, Robert C.; BIKLEN, Sari K. Investigação qualitativa em educação. Porto: Porto Editora, 1994.

BRASIL. Diretrizes Curriculares Nacionais Gerais para a Educação Básica Ministério da Educação, Secretária de Educação Básica. Diretoria de Currículos e Educação Integral. Brasília: MEC, SEB, DICEI, 2013.

BRASIL. Relatório Brasil no PISA 2018, versão preliminar. Ministério da Educação. INEP. Diretoria de Avaliação da Educação Básica (DAEB), Poder Executivo, Brasília, DF, p. 158, 2019. Disponível em:

http://download.inep.gov.br/acoes_internacionais/pisa/documentos/2019/relatorio_PISA 2018 _preliminar.pdf $>$. Acesso em: 20 set. 2020.

CHIN, Christine; OSBORNE, Jonathan. Students' questions: a potential resource for teaching and learning science. Studies in Science Education, v. 44, n. 1, p.1-39, 2008.

CONSTANTINO, Ana Luiza Alves; DORNELES, Aline Machado; MOTTA, Cezar Soares; SANTOS, Aline Silva dos. Pesquisa na Sala de Aula de Química: narrativas das aprendizagens da docência partilhada. Revista Insignare Scientia (RIS). v. 2, n. 2. Mai./Ago., p.240-254, 2019.

DEMO, Pedro. Desafios modernos da educação. 18. ed. Petrópolis: Vozes, 2012.

DEMO, Pedro. Educar pela pesquisa. 10. ed. Campinas: Autores Associados, 2015.

FREIRE, Paulo; FAUNDEZ, Antonio. Por uma pedagógica da pergunta. 7.ed. São Paulo: Paz e Terra, 2011.

FREIRE, Paulo; SHOR, Ira. Medo e ousadia: o cotidiano do professor. 4. ed. Rio de Janeiro: Paz e Terra, 1992.

HAGAY, Galit; BARAM-TSABARI, Ayelet. A shadow curriculum: Incorporating students' interests into the formal biology curriculum. Research in Science Education, V. 41, n. 5, p. 611-634, 2011.

KIEREPKA, Janice Silvana Novakowski; ZANON, Lenir Basso. Problematização e reconhecimento de teorias e práticas de professores em formação para o ensino de 
Ciências com foco no educar pela pesquisa. Revista Insignare Scientia (RIS), v. 2, n. 1. Jan./Abr., p.1-20, 2019

LIMA, Valderez Marina do Rosário; GRILLO, Marlene Correro. Como Organizar os conteúdos científicos de modo a contruir um currículo para o século 21? In.

GALIAZZIM Maria do Carmo, et al. Aprender em rede na Educação em Ciências. Editora UNIJUÍ, Ijuí, p.113-124, 2008.

MORAES, Márcia Cristina. Do ponto de interrogação ao ponto: a utilização de recursos da internet na educação pela pesquisa. In: MORAES, Roque; LIMA, Valderez Marina do Rosário (org.) (org.). Pesquisa em sala de aula: tendências para a educação em novos tempos. Porto Alegre: EDIPUCRS, p. 65-75, 2012.

MORAES, Roque; GALIAZZI, Maria do Carmo. Análise Textual Discursiva. 3. ed. Editora Unijuí, Ijuí, 2016.

MORAES, Roque; GALIAZZI, Maria do Carmo; RAMOS, Maurivan Güntzel. Pesquisa em sala de aula: fundamentos e pressuposto. In: MORAES, Roque; LIMA, Valderez Marina do Rosário (org.). Pesquisa em sala de aula: tendências para a educação em novos tempos. Porto Alegre: EDIPUCRS, p.11-20, 2012.

PAULETI, Fabiana. A pesquisa como princípio educativo no Ensino de Ciências: concepções e práticas em contextos brasileiros. Tese (Doutorado). Programa de PósGraduação em Educação em Ciências e Matemática, 2018. 131f.

RAMOS, Maurivan Güntzel. Educar para a pesquisa e educar a para a argumentação. In: MORAES, Roque; LIMA, Valderez Marina do Rosário (org.). Pesquisa em sala de aula: tendências para a educação em novos tempos. Porto Alegre: EDIPUCRS, p. 21$38,2012$.

SOUZA, F. Perguntas na Aprendizagem de Química no Ensino Superior. (2006). $530 \mathrm{f}$. Tese (Doutorado em Didáctica) - Departamento de Didáctica e Tecnologia Educativa, Universidade de Aveiro, Aveiro, 2006.

WERTSCH, James V. La mente en acción. Buenos Aires: Aique, 1999. 